DOI: 10.20472/IAC.2018.044.043

\title{
YUJI SATO
}

Graduate School of Management, Chukyo University, Japan

\section{DIFFERENCE IN RISK PERCEPTION OF UNCERTAINTIES IN SUPPLY CHAIN BETWEEN DEVELOPED AND DEVELOPING COUNTRIES}

\begin{abstract}
:
The objective of this paper is to clarify the relationship between uncertainties in supply chain and its disruption risk under environmental turbulence. Rapid spread of globalization pushes firms to face the higher level of uncertainty, which increases the risk of supply disruption. Firms must formulate necessary and sufficient strategy to supply chain management that they may confront. Such a strategy, however, involves a broad range of factors, including some that are subjective, e.g., risk perception. Formulating strategy for supply chain management and decision making for avoiding supply disruption thus must often rely heavily on past experience, generalities, and intuition. This paper addresses this issue by refining existing structural model of supply disruption. In the analyses, inner dependencies among demand, quality and logistics uncertainties, and outer dependencies between those uncertainties and the magnitude and the probability of disruption risks are evaluated. Pairwise evaluations among the uncertainties and those between representations of supply disruption risk and uncertainties comprise a prioritized analysis. Case studies are conducted in beverage companies that engage in business both in developed and developing countries, which demonstrate the applicability of the prioritized analyses based on the proposed structural model to the real markets. The results clarify the difference in risk perceptions under environmental backgrounds and illustrate the feature of risk perception based on the characteristics of companies. According to the retrospective interview after the case study, the managers in the companies are provided suggestion on how to formulate a strategy to their supply chain management.
\end{abstract}

\section{Keywords:}

supply chain management; supply disruption; risk perception; uncertainty.

JEL Classification: C44, D81 